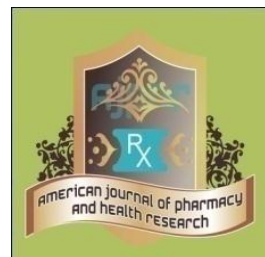

Research Article
AMERICAN JOURNAL OF PHARMACY AND HEALTH RESEARCH
www.ajphr.com

2018, Volume 6, Issue 06

ISSN: 2321-3647(online)

\title{
In-Vitro Anticoagulant and Clot-Lysis Potential of Aqueous Extract of Datura Metel L.
}

\author{
Ashok A. Muchandi ${ }^{*}$, Nitin S. Thorat ${ }^{2}$, Suhas R. Mahanwar ${ }^{2}$ \\ 1.Department of Pharmacology, Adarsh College of Pharmacy, Vita, Maharashtra, India \\ 2.Adarsh College of Pharmacy, Vita, Maharashtra, India
}

\begin{abstract}
Thromboembolic disorders affecting millions of people worldwide. Presently available anticoagulants are closely related to antiplatelet drugs and thrombolytic drugs by manipulating the various pathways of blood coagulation but having limited use due serious side effects. A medicinal herb Datura metel belongs to family Solanaceae, has been widely used in traditional medicine. In the present study, different concentrations $(20-100 \mu \mathrm{g} / \mathrm{ml})$ of aqueous extract of leaves of Datura metel was evaluated for in-vitro anticoagulant and clot lysis activity. The results showed that, there was concentration dependent increase in anticoagulant activity as a measure of increased prothrombin time activity. Similarly, there was concentration dependent increase in percentage clot lysis activity. A maximum $23.81 \%$ clot lysis activity was reported at concentration $100 \mu \mathrm{g} / \mathrm{ml}$ of extract. Thus, it was concluded that, aqueous extract of leaves of Datura metel has potential in-vitro anticoagulant and clot lysis activity and may be beneficial in the treatment of cardiovascular diseases.
\end{abstract}

Keywords: Clot lysis, cardiovascular diseases, prothrombin time, anticoagulants, 


\section{INTRODUCTION}

Thrombosis is one of the leading causes of thromboembolic disorders affecting million persons worldwide. A thrombus develops in the circulatory system due to failure of hemostasis which causes vascular blockage and while recovering leads to serious consequences in thrombotic disease such as myocardial or cerebral problems, at times leading to death ${ }^{1}$. Anticoagulants are known to be blood thinners, which are chemical substance that prevent or reduce coagulation of blood, prolonging the clotting time. As a class of medication, anticoagulants are used in therapy for thrombotic disorders. Some anticoagulants are used in medical equipment, such as test tubes, serum-separating tubes, blood transfusion bags, and dialysis equipment ${ }^{2}$. Anticoagulants are closely related to antiplatelet drugs and thrombolytic drugs by manipulating the various pathways of blood coagulation specifically, inhibit platelet aggregation whereas anticoagulants inhibit the coagulation cascade by clotting factors that happens after the initial platelet aggregation. Common anticoagulants include warfarin, heparin and vitamin $\mathrm{K}$ and their derivatives have been the major players in the clinical setting ${ }^{3,4}$. Thrombolytic agents that include tissue plasminogen activator (t-PA), urokinase (UK), and streptokinase (SK) are used across the world for the treatment of these diseases. In India, though streptokinase and urokinase are widely used due to lower cost, as compared to other thrombolytic drugs. But due to the weak substrate specificity of these first generation drugs, they lead to systemic fibrinolysis, anaphylactic reaction, and bleeding complication. Again, multiple treatments with streptokinase are restricted in a given patient as a result of immunogenicity. Because of the shortcomings of the available thrombolytic drugs, attempts are underway to develop improved recombinant variants of these drugs ${ }^{5}$. Hence, it is needed to find out the safe, less or no side effective herbal drugs, because natural products of higher plants may give a new source of thrombolytic agents.

Several plants used for the treatment of thromboembolic diseases in different system of traditional medicine have shown anticoagulant and or antithrombotic activity and such plants claimed in the traditional system still remain to be scientifically investigated. A medicinal herb Datura metel L. which is under the family of Solanaceae grows in warmer parts of the world particularly in south and Southeast Asia including India and Sri Lanka. It was traditionally used in treating asthma, cough, burns and ulcer ${ }^{6}$. Scientifically it was proved for antifunga ${ }^{17}$, hypoglycemic ${ }^{8}$, xanthine oxidase inhibitory activity ${ }^{9}$, free radical scavenging activity ${ }^{10}$ and antiproliferative activity ${ }^{11}$. The whole plant of Datura metel contains scopolamine and atropine 
while leaves showed to posses' daturilin, withametelin C, D, and E and and various trigloyl esters of tropine and pseudotropine ${ }^{8,12}$.

Thus, based on literature survey, in the present study, aqueous extract of leaves of medicinal plant Datura metel was investigated for its in-vitro anticoagulant and clot lysis activity.

\section{MATERIALS AND METHOD}

\section{Drugs and reagents}

Ethamsylate (FDC. India), Aspirin (USV Pvt. Ltd, India), Thromboplastin reagent (Helena Laboratories, USA). $0.1 \%$ Calcium chloride. All other reagents and chemicals were off analytical grade.

\section{Collection of plant material and authentication}

The fresh leaves of Datura metel L. were collected from local region of Sangli District, Maharashtra, India. Further, the herbarium of plant material was prepared and authenticated by Dr. S. M. Shendage, Department of Botany, Balwant College, Vita, Maharashtra, India (Voucher no: 4/2017-18).

\section{Preparation of aqueous extract}

Leaves were washed properly with distilled water and dried under sunlight. About $250 \mathrm{~g}$ of the dried leaves were cut in to small pieces grinded to a fine powder. The $100 \mathrm{~g}$ of the fine powder was suspended in $200 \mathrm{ml}$ distilled water in a conical flask and carried to overnight continue shaking with the help of mechanical shaker. The supernatant of extract was filtered by using Whatman's filter paper. The excess solvent was evaporated and solid residue gathered was collected into the petri dish for further in-vitro investigation. The percentage yield of extract obtained was $1.6 \%$.

\section{Collection of blood sample and preparation of serum and plasma}

About $10 \mathrm{ml}$ blood sample was drawn via vein puncture method from healthy volunteer. The blood placed separately in containers containing sodium citrate to prevent the clotting process. Centrifugation (2500 g, for $10 \mathrm{~min}$ ) was carried out to separate the blood cells from plasma in order to obtain pure platelet plasma for prothrombin time test ${ }^{13}$.

\section{Anticoagulant assay}

Anticoagulation assay was performed as a measure of prolongation of prothrombin activity. Briefly, $0.2 \mathrm{ml}$ of thromboplastin reagent was taken in to different set of test tubes containing 0.2 $\mathrm{ml}$ of different concentrations $(20-100 \mu \mathrm{g} / \mathrm{ml})$ of extract. Aspirin was used as standard while blank test tube contains distilled water. Warm the test tubes at $37^{\circ} \mathrm{C}$ and inject $0.2 \mathrm{ml}$ of plasma 
and mix the contents of the tube. Then add $0.2 \mathrm{ml}$ calcium chloride reagent to each test tube. Hold the tubes so that contents can be monitored for the formation of the clot. Gently tilt the tube back and forth until a clot forms, note the time immediately. Further, the solution was taken on glass slide and observed under microscope for observation of clot. All the tests were performed in triplicate ${ }^{14}$.

\section{In vitro clot lysis activity}

The clot lysis activity of plant extract was carried out using the method of Prasad et al., 2006 with slight modification ${ }^{15}$. The sterile Appendorf's tubes were weighed and weight of each tube was noted. About $2.5 \mathrm{ml}$ of blood was collected into each tube and incubated at $37{ }^{\circ} \mathrm{C}$ for 45 minute to allow blood clot. After clot formation, serum was completely removed without disturbing the clot and each tube having clot was again weighed to determine the clot weight (clot weight $=$ weight of clot containing tube - weight of tube alone). To each tube containing pre-weighed clot, add different concentrations of extract (20-100 $\mu \mathrm{g} / \mathrm{ml})$. Ethamsylate was taken as standard drug and sterile water was added to the blank tube. All the tubes were then incubated at $37{ }^{\circ} \mathrm{C}$ for $90 \mathrm{~min}$ and observed for clot lysis. After incubation, fluid released was removed and tubes were again weighed to observe the differences in weight after the clot disruption. Difference in weight was taken before and after the clot lysis and it was expressed as percentage of clot lysis. Percentage of clot lysis was calculated using the formula, Percentage clot lysis $=\{$ Weight of clot after lysis/Weight of clot before lysis $\}$ X 100

\section{RESULTS AND DISCUSSION}

\section{Effect on prothrombin time activity (Anticoagulant activity)}

The effect of different concentration of plant extracts on prothrombin time activity was mentioned in Table 1. In this study concentration dependent increase in prothrombin time activity was observed and thus increases period for clot formation. The maximum prothrombin time activity $(4.10 \pm 0.13 \mathrm{~s})$ was observed at concentration $100 \mu \mathrm{g} / \mathrm{ml}$. However, the blank showed reduced prothrombin time activity $(1.54 \pm 0.10 \mathrm{~s})$ and immediate formation of blood clot as compared to standard drug and test extracts. The standard drug aspirin also showed increased prothrombin time activity $(4.35 \pm 0.12 \mathrm{~s})$ and delayed clot formation.

Further, the presence of clot size and density of clot in the solution was observed under microscope. Blank test tube showed presence of larger clot size and more density of clot whereas standard and extract showed decreased clot size and clot density as compared to blank (Fig. 1). 
Table 1. Effect of different concentrations of aqueous extract of leaves of Datura metel on prothrombin time activity (Anticoagulant activity).

\begin{tabular}{ll}
\hline Concentrations & $\begin{array}{l}\text { Prothrombin time activity } \\
\text { (min) }\end{array}$ \\
\hline Blank & $1.54 \pm 0.10$ \\
Aspirin $100 \mu \mathrm{g} / \mathrm{ml}$ & $4.35 \pm 0.12$ \\
AEDM $20 \mu \mathrm{g} / \mathrm{ml}$ & $2.45 \pm 0.11$ \\
AEDM $40 \mu \mathrm{g} / \mathrm{ml}$ & $3.05 \pm 0.14$ \\
AEDM $60 \mu \mathrm{g} / \mathrm{ml}$ & $3.25 \pm 0.17$ \\
AEDM $80 \mu \mathrm{g} / \mathrm{ml}$ & $3.45 \pm 0.11$ \\
AEDM $100 \mu \mathrm{g} / \mathrm{ml}$ & $4.10 \pm 0.13$ \\
\hline
\end{tabular}

Each value is mean \pm SEM of three observations. AEDM= aqueous extract of Datura metel.
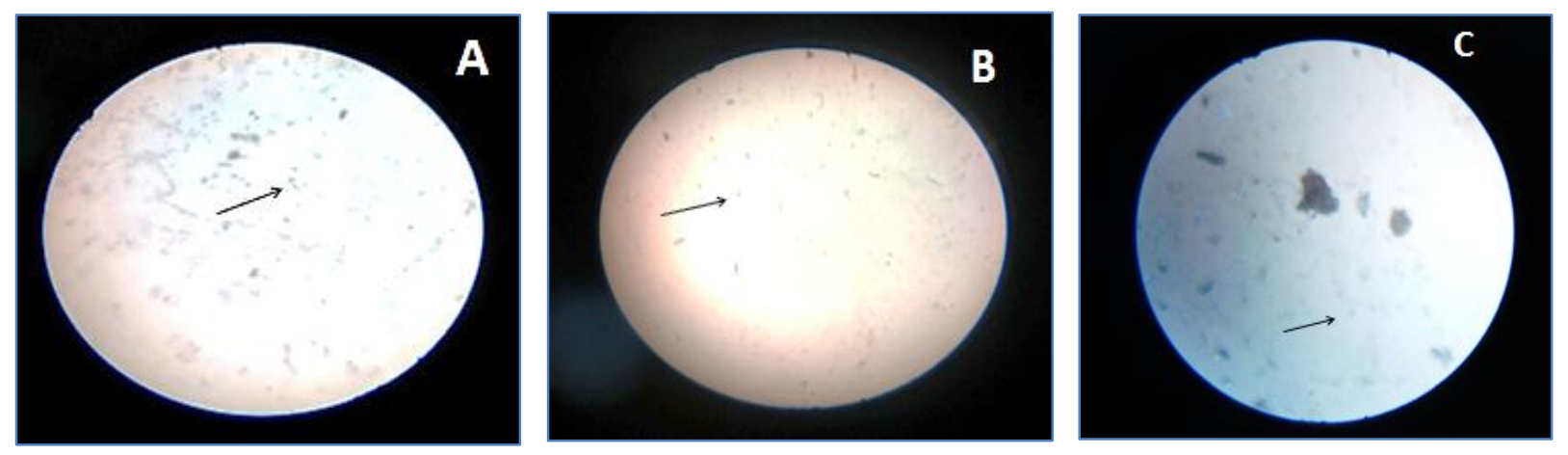

Figure 1. photographs of effect of aqueous extract on clot size and clot density observed under microscope. A. Normal B. In presence of Aspirin $\quad$ C. In presence of aqueous extract.

Each value is mean \pm SEM of three observations. AEDM= aqueous extract of Datura metel (Arrow) $\longrightarrow$ indicates presence of blood clot.

\section{Effect on clot lysis activity}

The effect of plant extract on clot lysis was shown in Table 2. There was concentration dependent decreased clot weight and increased clot lysis in extract treated tube as compare to blank tube. Similarly, more clots were dissolved in standard treated tube as compare to blank. The percentage clot lysis of blank tune showed $0.58 \%$ and that of standard drug aspirin showed $31.64 \%$. The maximum $23.81 \%$ clot lysis activity was observed at highest concentration 100 $\mu \mathrm{g} / \mathrm{ml}$ of aqueous extract of leaves of Daturaa metel (Fig.2). 
Table 2. Effect of different concentrations of aqueous extract of leaves of Datura metel on clot lysis activity.

\begin{tabular}{llll}
\hline Concentrations & \multicolumn{2}{l}{ Weight of clot $(\mathbf{g})$} & \multirow{2}{*}{$\%$ Clot lysis } \\
\cline { 2 - 3 } & Before lysis & After lysis & \\
\hline Blank & $1.73 \pm 0.11$ & $1.72 \pm 0.19$ & $0.58 \%$ \\
Aspirin $100 \mu \mathrm{g} / \mathrm{ml}$ & $1.96 \pm 0.13$ & $1.34 \pm 0.11$ & $31.64 \%$ \\
AEDM $20 \mu \mathrm{g} / \mathrm{ml}$ & $1.89 \pm 0.12$ & $1.83 \pm 0.15$ & $3.18 \%$ \\
AEDM $40 \mu \mathrm{g} / \mathrm{ml}$ & $1.92 \pm 0.16$ & $1.81 \pm 0.13$ & $5.73 \%$ \\
AEDM $60 \mu \mathrm{g} / \mathrm{ml}$ & $1.87 \pm 0.13$ & $1.69 \pm 0.17$ & $9.63 \%$ \\
AEDM $80 \mu \mathrm{g} / \mathrm{ml}$ & $1.88 \pm 0.15$ & $1.57 \pm 0.12$ & $16.49 \%$ \\
AEDM $100 \mu \mathrm{g} / \mathrm{ml}$ & $1.89 \pm 0.17$ & $1.44 \pm 0.14$ & $23.81 \%$ \\
\hline
\end{tabular}

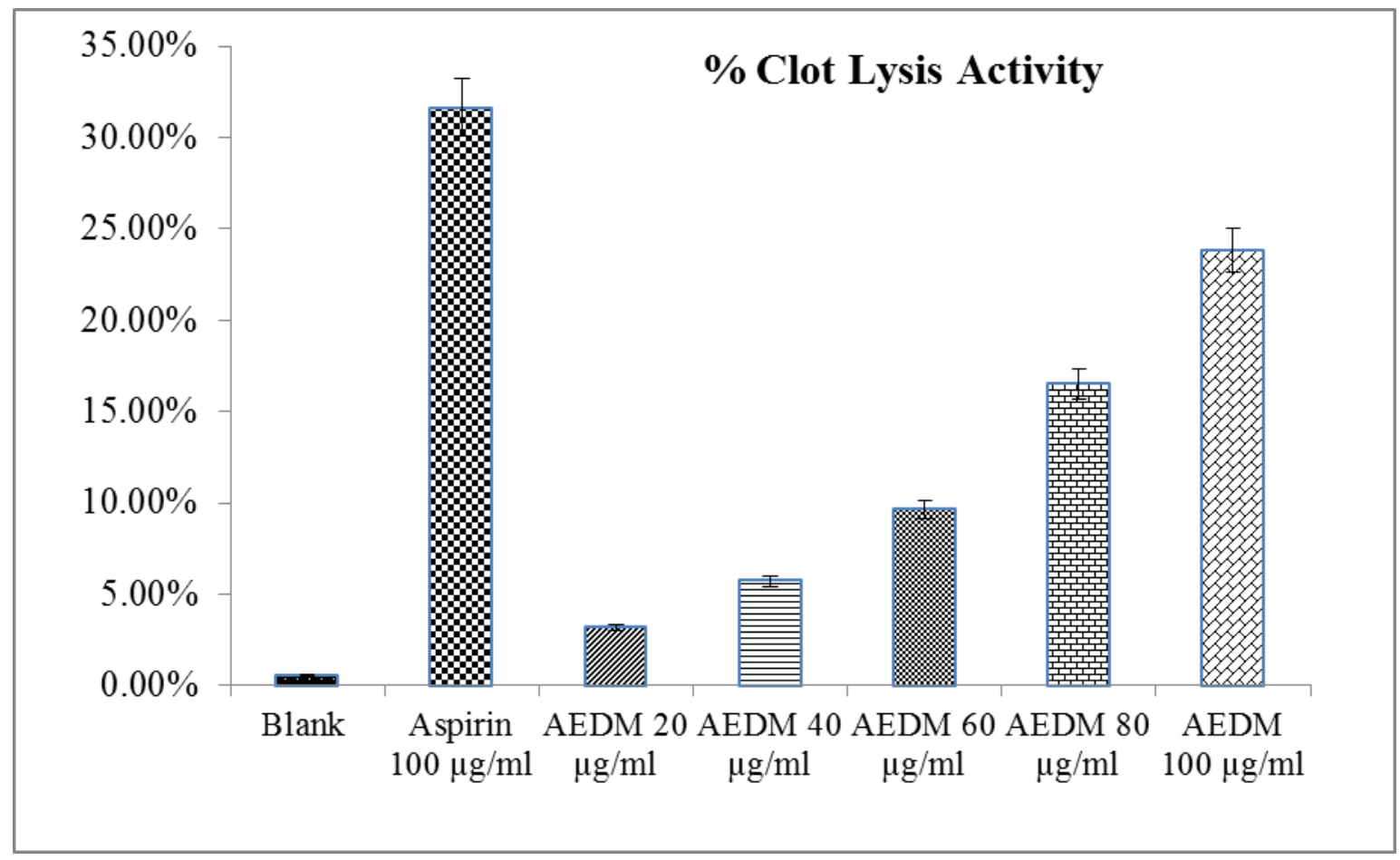

Figure 2. Effect of different concentrations of aqueous extract of leaves of Datura metel on percentage clot lysis activity. Each value is mean \pm SEM of three observations. AEDM= aqueous extract of Datura metel.

\section{DISCUSSION}

Plants have the ability to synthesize a wide variety of chemical compounds that are used to perform important biological functions. Many of these phytochemicals have beneficial effects on long term health when consumed by humans and can be used to effectively treat human diseases. In recent years, naturally occurring chemical substance derived from plants have attracted interest as possible treatment for coagulation disorder and as template molecules for the development of new drugs. Since the drug used for the cardiovascular diseases are not 
economical and not accessible to the greater section of the society and they cause side effects, herbal drugs are having less or no side effects and application of phytomedicine may be a born for the cardiovascular diseases.

Coagulation is a process that occurs mainly due to the complex interaction of cellular and molecular components. Initially clotting involves common pathway of both intrinsic and extrinsic pathways, but lately, it found to be due to a balance between the procoagulants and anticoagulants. Prothrombin is involved in pathway of blood coagulation mechanism ${ }^{16}$. Since, prolongation of prothrombin time activity in extract treated tube is an indication of inhibition of prothrombin action. On the other hand, Clot lysis may be the result of the combinatorial effect of the active compounds present in the plant.

\section{CONCLUSION}

The aqueous extract of leaves of Datura metel has potential in-vitro anticoagulant and clot lysis activity and thus may be useful in the treatment of cardiovascular diseases caused by abnormal blood clot. Further isolation, characterization of active constitutes responsible for underlying mechanism is necessary.

\section{ACKNOWLEDGMENT}

The authors are thankful to Principal, Adarsh College of Pharmacy, Vita for technical and laboratory support throughout the research work.

\section{REFERENCES}

1. Ng VL. Prothrombin time and partial thromboplastin time assay consideration. Clin Lab Med 2009; 29(2): 253-263.

2. Alagesapoobathi C. Afr J Trad CAM 2009; 6(3): 222-227.

3. Ali M, McDonald JWD. Thrombosis Research 1978; 13: 1057-1065.

4. Sliver MJ, Koch JJ, Ingeman CM. Science 1974; 183: 1085-1087,

5. Colman RW, Hirsh J, Marder VJ. Haemostasis and thrombosis, basic principle and clinical practice, Lippincott Company, 1994; 759-762.

6. Nadkarni KM. Indian Materia Medica, Popular Prakashan, Bombay, 1976.

7. Ma L, Xie CM, Li J, Lou FC, Hu LH. Daturametelins H, I, and J: three new withanolide glycosides from Datura metel L. Chemistry \& Biodiversity 2006; 3(2):180-186.

8. Rajesh GLS. Studies on antimycotic properties of Datura metel. Journal of Ethnopharmacology 2002; 80:193-197. 
9. Murthy BK, Nammi S, Kota MK, Rao RVK, Rao NK, Annapurna A. Evaluation of hypoglycemic and antihyperglycemic effects of Datura metel (Linn.) seeds in normal and alloxan-induced diabetic rats. Journal of Ethnopharmacology 2004; 91: 95-98.

10. Umamaheswari M, AsokKumar K, Somasundaram A, Sivashanmugam T, Subhadradevi V, Ravi TK. Xanthine oxidase inhibitory activity of some Indian medical plants. Journal of Ethnopharmacology 2007; 109: 547-551.

11. Ramadan MZ, Zayed R, El-Shamy H. Screening of bioactive lipids and radical scavenging potential of some solanaceae plants Food Chemistry 2007; 103: 885-890.

12. Afsharypuor S, Mostajeran A, Mokhtary R. Variation of scopolamine and atropine in different parts of Datura metel during development. Planta Med 1995; 61: 383-384.

13. Biggs R, McFarlane R. Human Blood Coagulation and their disorders, Blackwell Scientific Publications, Oxford1962; 430-436.

14. Quick AJ. Bleeding Problems in Clinical Medicine. W.B. Saunders Company, Philadelphia.1970.

15. Prasad S, Kashyap RS, Deopujari JY, Purohit HJ, Taori GM, Daginawala H.F. Development of an in vitro model to study clot lysis activity of thrombolytic drugs. Thrombosis Journal 2006; 4: 1-6.

16. Hoffman M, Monroe DM. Coagulation 2006: A modern view of hemostasis. Hematol Oncol Clin North Am 2007;21:1-11. 